\title{
Allergy and school: nothing to be sneezed at!
}

\section{A primary school project in Bielefeld, Germany, on epidemiology and health promotion in allergic diseases}

\author{
Reinhard Bornemann ${ }^{1}, 2$, Katharina Hagemeister ${ }^{3}$, Hans-Georg Bresser ${ }^{3}$, Eckard Hamelmann ${ }^{3}$ \\ ${ }^{1}$ Working Group 2: Public Health Medicine, Faculty of Health Sciences, Bielefeld University, Bielefeld, Germany; \\ 2Department of Internal Medicine, Bielefeld Clinical Centre, Bielefeld, Germany; ${ }^{3}$ Pediatric Allergology/ \\ Pneumology, Children's Center Bethel, Evangelical Hospital, Bielefeld, Germany
}

\begin{abstract}
Background: Allergic diseases account for the largest proportion of chronic diseases in childhood and adolescence and place a significant burden on everyday family, social, and in particular school life. Without appropriate education, affected individuals often have little of the knowledge required to understand and deal safely with their allergic disease, and their social environment (school) generally offers insufficient information. An interdisciplinary project involving the Bielefeld Community Foundation ("Bielefelder Bürgerstiftung”), the Children's Center Bethel, and the local school authority investigated the current knowledge, possibilities for increasing that knowledge, as well as pupils' and teachers' perception of the problems experienced by fellow pupils, while at the same time collecting current prevalence figures on allergic diseases among primary school children.

Methods: All Bielefeld primary schools were invited to participate in the 3 years between 2008 and 2010. A teaching session on allergic diseases held by specialists from the pediatric hospital formed the core of the project. A standardized survey of children - which also addressed non-affected children for the first time in Germany - on the effects of, their knowledge of, and their attitudes toward allergic diseases, as well as an assessment of their quality of life (cross-sectional study), was conducted prior to and following each session. Parents were also surveyed.
\end{abstract}

Results: In all, 24 schools per year, each with around 60 classes and 1,250 pupils aged 9 years, took part between 2008 and 2010. Approximately $30 \%$ reported suffering from an allergic disease themselves, of which - with regard to single entries - $16 \%$ were "allergies," $4 \%$ "asthma," and $5 \%$ atopic dermatitis. Figures collected from parents were only slightly lower than those from their children. Clear deficits that existed in terms of factual knowledge and/or correct conduct in allergic disease - among affected children as well as in their social environment - prior to the education program were noticeably improved by the teaching session.

Discussion: The prevalence data gathered here confirm the high numbers recently found in the KiGGS study. Thus, allergic diseases represent a considerable disease risk and potential burden in school children. Providing affected children and their social environment (teachers, fellow pupils) with specialist education can bring about considerable improvements in everyday school life.

Cite this as Bornemann R, Hagemeister K, Bresser HG, Hamelmann E. Allergy and school: nothing to be sneezed at! A primary school project in Bielefeld, Germany, on epidemiology and health promotion in allergic diseases. Allergo J Int 2016;25:201-9

DOI: 10.1007/s40629-016-0131-3

\section{Keywords}

allergic rhinitis bronchial asthma

- atopic dermatitis - primary school asthma education

- atopic dermatitis education

\section{Submitted}

January 7, 2016

\section{Accepted}

February 17, 2016

German version www.springermedizin.de/ allergo-journal 


\begin{tabular}{|c|c|}
\hline \multicolumn{2}{|c|}{ Abbrevations } \\
\hline DAPG & $\begin{array}{l}\text { German Academy for Prevention } \\
\text { and Health Promotion ("Deutsche } \\
\text { Akademie für Prävention und } \\
\text { Gesundheitsförderung e.V.") }\end{array}$ \\
\hline HTA & Health technology assessment \\
\hline $\lg E$ & Immunoglobulin $\mathrm{E}$ \\
\hline KiGGS & $\begin{array}{l}\text { German Children and Adolescent } \\
\text { Health Survey ("Kinder- und Jugend- } \\
\text { gesundheitssurvey") }\end{array}$ \\
\hline LZG.NRW & $\begin{array}{l}\text { Nordrhein-Westfalen Center for Health } \\
\text { (Landeszentrum Gesundheit Nord- } \\
\text { rhein-Westfalen) }\end{array}$ \\
\hline RKI & Robert Koch Institute \\
\hline TS & Teaching session \\
\hline TOI & Time of investigation \\
\hline
\end{tabular}

\section{Background}

Allergic diseases take first place among chronic diseases in childhood and adolescence: according to the 2003-2006 German Children and Adolescent Health Survey ("Kinder- und Jugendgesundheitssurvey”, KiGGS; basic examination) conducted nationwide by the Robert Koch Institute (RKI), the combined 12-month prevalence of asthma, hay fever, and atopic eczema/dermatitis was $16.7 \%$ [1]. This figure was confirmed in the 2009-2012 fol-

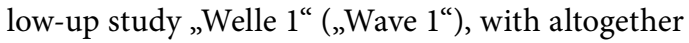
$17.0 \%$ of individuals being affected by at least one of the atopic diseases mentioned above.

In addition to the direct health-related impairments these diseases cause, they also result in a sometimes considerable burden on the individual in everyday social and, in particular, school life; increased absenteeism, reduced participation in physical education classes, reduced ability to concentrate, comparatively worse grades, as well as stigmatization and social exclusion $[1,3,4]$.

This baseline situation led to an interdisciplinary primary school project in Bielefeld, Germany, in 2006: on the initiative of the Bielefeld Community Foundation ("Bielefelder Bürgerstiftung"), which focused on children and adolescents, a collaboration was initiated with the Children's Center Bethel of the Bielefeld Evangelical Hospital (EvKB) and the Bielefeld school authority. On the basis of the good response to a 2007 pilot project, the decision was taken to extend the project and include scientific research. This was followed by yearly project phases; the present article reports on the years 2008-2010. The goals of the project were to convey basic information, generally increase pupils' safety in dealing with their allergic disease, and promote sensitization to and tolerance for affected fellow pupils, as well as to gather data on the prevalences of allergic diseases and the level of knowledge and attitudes among primary school children in relation to these diseases.

\section{Methods}

The study population comprised third graders, i.e., children aged around 9 years. The majority of allergic symptoms have already become manifest by this age [1], in addition to which this age group is capable of adequately following a respective course of instruction and taking part in a survey [5].

There are 48 primary schools in Bielefeld: $46 \mathrm{mu}-$ nicipal and two confessional schools. All schools received a written invitation to take part in the project from the local school authority. In participating schools, information evenings for parents and school personnel were organized.

The core of the project was a 2 -h teaching session (TS) held by specially trained and experienced professionals from the Children's Center (specialist pediatric nurses, some with an additional qualification as prevention assistants, asthma and atopic dermatitis trainers, and lecturers from the German Academy for Prevention and Health Promotion in Childhood and Adolescence ["Deutsche Akademie für Prävention und Gesundheitsförderung im Kindes- und Jugendalter e. V.", DAPG]), aimed at conveying "child-oriented" knowledge on and promoting attitudes toward allergies, asthma, and atopic dermatitis.

The educational content of the TS: children were divided into small groups and given "topic boxes" containing materials on allergies, asthma, and atopic dermatitis. They were then given basic information on the structure and function of the relevant organs or systems. Exercises in self-awareness of the disease symptoms, e.g., breathing through a straw, formed an essential part of the sessions. To conclude, rules on how to respond to classmates affected with allergic diseases were proposed. Further details can be found on the project website [6]. TS were all conducted in the second half of the school year.

Data was collected using questionnaires completed by the children during class time 1 week before and 1 week after the TS - at both the first and second time of investigation (TOI). The questionnaire covered 20 items altogether: 10 on the extent to which children were themselves affected by allergic disease and their knowledge of or attitudes to these diseases, as well as 10 on health-related quality of life („KIDSCREEN ${ }^{\circledR}$-10 Index“ [7]; see [8] for more details on methodology). The extent to which children were themselves affected was ascertained with the following questions: "Do you yourself suffer 
from an allergy, asthma, or atopic dermatitis?" and (if yes) "Please specify."

At the first TOI, children were also given questionnaires for their parents, which were collected at the second TOI. Parents were asked: "Has your child suffered from an allergy, asthma, or atopic dermatitis in the last 12 months?" and again asked to specify in the case of a positive response. Possibly available medical data was not retrieved.

In order to assess the extent to which the effects of the education program were sustained, data was collected in a follow-up questionnaire completed by the fourth graders that had participated in 2010 as third graders. The fourth graders completed the same questionnaire as the year before; this time, however, without a prior TS [9].

Data storage and analysis were carried out using IBM SPSS Statistics (v.20). The McNemar test - to assess the effect of the education program - and the Wilcoxon test - to assess the effect of the intervention on health satisfaction - were used as statistical tests.

\section{Results \\ Study collective}

In all, 24 of the 48 Bielefeld primary schools (accounting for around 60-65 of all 140 third grades, i.e., 1,500 of all approximately 3,200 third graders in Bielefeld) took part in the project in each of the 3 years between 2008 and 2010. The survey was conducted in 23 schools / 59 classes in 2008, 24 schools / 65 classes in 2009, and 24 schools / 62 classes in 2010.

The numbers of analyzable questionnaires were as follows: 2008, 1,216 at the first and 1,211 at the second TOI; 2009, 1,389 and 1,128, respectively; $2010,1,279$ and 1,213, respectively. These included the following numbers of complete pairs of corresponding questionnaires completed at the first and second TOI by the same children, thereby permitting intra-individual before-and-after comparisons: 2008, from 1,028 children; 2009 from 905 children; and 2010 from 685 children.

In each of the 3 years, complete data on age and sex were obtained from $97 \%-98 \%$ of questionnaires at the first TOI. The average age was 8.9 years in all 3 years, with a standard deviation of 0.6 and a median of 9 years. The age range was $7-11$ years for all years; however, only a scant number of children were aged 7 (2008-2010: $\mathrm{n}=2,7$, and 11, respectively) or 11 years ( $\mathrm{n}=13,11$, and 4 , respectively). The gender ratio was evenly balanced, with girls accounting for between $49 \%$ and $50 \%$ in all 3 years (Tab. 1).

\section{Epidemiological data}

Over the 3 years, $29.3 \%-33.8 \%$ of children answered positively to the question: "Do you yourself suffer from an allergy, asthma, or atopic dermatitis?"
Children were able to provide additional, free textbased information to the question: "Please specify." The information most frequently given here related to "allergies," "asthma," and "atopic dermatitis." A number of children made multiple entries relating to allergic diseases. Results were subdivided accordingly into "single responses" relating to the above-mentioned allergic diseases and "cumulative entries," including "multiple entries." Conditions that could not be classified as allergic disease were recorded under "others." Relatively constant rates were seen over the 3 years for: allergies, $16 \%$ "single" and $18 \%$ "cumulative"; asthma, $4 \%$ and $6 \%$, respectively; atopic dermatitis, $5 \%$ and $7 \%$, respectively (Tab. 2).

A further difference was seen in how information on disease changed: a slight rise in rates was observed between the first and second TOI in two of the three survey years; although these were very low for "allergies" and "asthma," the rates for "atopic dermatitis" rose by over $50 \%$, from around $4.5 \%$ to $6.5 \%$.

At the first TOI, parents were asked whether their child had developed an "allergy," "asthma," or "atopic dermatitis" within the previous 12 months. Parent information was largely in line with that provided by their children (Tab. 2). Looking at the diseases individually, one notices that parent data on "allergies" and "asthma" pointed to a slightly lower

Tab. 1: Participation and demographic data

\begin{tabular}{|l|l|l|l|}
\hline & 2008 & 2009 & 2010 \\
\hline $\begin{array}{l}\text { Respondents (n) } \\
\text { Child respondents in 1st TOI }\end{array}$ & 1,216 & 1,389 & 1,279 \\
\hline Child respondents in 2nd TOI & 1,211 & 1,128 & 1,213 \\
\hline Matches between 1st and 2nd TOI & 1,028 & 905 & 685 \\
\hline Parent respondents & 925 & 1,191 & 1,119 \\
\hline Children's age & & & \\
\hline Mean (SD; median) & $8.9(0.6 ; 9)$ & $8.9(0.6 ; 9)$ & $8.9(0.6 ; 9)$ \\
\hline 7 years & 2 & 7 & 3 \\
\hline 8 years & 275 & 307 & 311 \\
\hline 9 years & 776 & 888 & 795 \\
\hline 10 years & 127 & 149 & 132 \\
\hline 11 years & 13 & 11 & 4 \\
\hline girl : boy distribution & & & \\
\hline (\%) All relating to the 1st TOI & $49,0: 51,0$ & $49,9: 50,1$ & $49,1: 50,9$ \\
\hline SD, Standard deviation; TOI, time of investigation & & & \\
\hline
\end{tabular}




\section{Tab. 2: Children affected by allergic diseases: self-reported and parent information}

\begin{tabular}{|c|c|c|c|c|c|c|c|c|}
\hline & \multicolumn{2}{|c|}{2008} & \multicolumn{2}{|c|}{2009} & \multicolumn{2}{|c|}{2010} & \multirow[t]{2}{*}{$\begin{array}{l}\text { KiGGS } \\
2007^{d}\end{array}$} & \multirow[t]{2}{*}{$\begin{array}{l}\text { KiGGS } \\
2013^{d}\end{array}$} \\
\hline & $\begin{array}{l}\text { Children } \\
2^{\text {nd }} \mathrm{TO}\end{array}$ & Parents & $\begin{array}{l}\text { Children } \\
2^{\text {nd }} \mathrm{TO}\end{array}$ & Parents & $\begin{array}{l}\text { Children } \\
2^{\text {nd }} \mathrm{TO}\end{array}$ & Parents & & \\
\hline Total number & 1,211 & 925 & 1,128 & 1,191 & 1,213 & 1,119 & & \\
\hline Total number affected & 367 & 254 & 381 & 328 & 355 & 304 & & \\
\hline Total percentage affected & 30.3 & 27.5 & 33.8 & 27.5 & 29.3 & 27.2 & & \\
\hline $\begin{array}{l}\text { Percentage affected by allergy, asthma, atopic } \\
\text { dermatitis }^{a}\end{array}$ & 24.8 & 20.4 & 27.3 & 19.8 & 24.2 & 20.1 & 16.7 & 17.0 \\
\hline "Not" affected (\%) & 58.1 & 68.2 & 58.9 & 70.0 & 59.2 & 70.8 & & \\
\hline “Don't know / n.a.” whether affected (\%) & 11.6 & 4.3 & 7.4 & 2.4 & 11.5 & 2.1 & & \\
\hline Single entry for allergy (\%) & 15.6 & 11.9 & 17.5 & 13.3 & 14.4 & 12.4 & 8.7 & 8.2 \\
\hline Allergies cumulated (\%)c & 17.3 & 15.1 & 20.4 & 18.1 & 16.2 & 17.3 & & \\
\hline Single entry for asthma (\%) & 4.0 & 2.7 & 4.3 & 2.4 & 4.5 & 2.4 & 3.2 & 3.4 \\
\hline Asthma cumulated (\%) & 5.9 & 5.4 & 7.0 & 5.8 & 5.8 & 6.1 & & \\
\hline Single entry for atopic dermatitis (\%) & 5.2 & 5.8 & 5.6 & 4.1 & 5.2 & 5.3 & 7.8 & 5.4 \\
\hline Atopic dermatitis cumulated (\%) & 6.6 & 7.8 & 7.0 & 6.9 & 6.3 & 7.2 & & \\
\hline Multiple entries (\%) & 2.4 & 3.8 & 3.3 & 5.1 & 2.0 & 5.1 & & \\
\hline Others (\%) & 1.6 & 2.7 & 1.2 & 2.4 & 1.2 & 1.7 & & \\
\hline Not specified (\%) & 1.6 & 0.5 & 2.0 & 0.3 & 2.0 & 0.3 & & \\
\hline
\end{tabular}

incidence than did the children's data - parent data on "atopic dermatitis," however, indicated a higher incidence.

In addition to data on allergic diagnoses, it was also possible to identify factors that were linked to these diseases and which were classified into various categories for analysis purposes (Tab. 3). We subdivided these reported factors into "specific allergens" and "nonspecific triggers," whereby the "specific allergens" are clearly defined; for "nonspecific triggers," on the other hand, data such as "sun allergy," "citrus fruits"/"other fruits," as well as other foodstuffs, care products, drugs, etc., that are not clearly linked to allergies were recorded.

In all 3 years, "house dust mite (feces)" and "tree/ grass pollen" were the most frequently reported "specific allergens," followed by "animals/animal hair (dander)."

Similarly, any entries made by the parents were recorded and compared with those of their children. Parents reported more "specific allergens," or fewer "nonspecific" triggers, compared with their children; overall, however, parent data on allergies were largely in line with the children's data in terms of allergen identification and frequency (Tab. 3).

In $2008,65.6 \%$ and $78.5 \%$ of children responded at the first and second TOI, respectively, with "Yes" to the question "Do you know a child that has an allergy, asthma, or atopic dermatitis?"; in 2009 , these figures were $64.9 \%$ and $80.6 \%$, respectively, and in $201068.5 \%$ and $80.5 \%$, respectively. In other words, TS raised awareness among children of their fellow pupils' disease by $12 \%-15 \%$.

\section{Questions on knowledge and behavior}

The children's level of knowledge and behavioral attitudes toward allergic diseases were surveyed using seven questions considered relevant on the basis of experience gained in allergy and asthma training. Only the responses of children for whom questionnaires from the first and second TOI were available were analyzed, in order to ensure before-and-after comparisons in the sense of a paired sample. 
Tab. 3: Allergen entries: child and parent information

\begin{tabular}{|c|c|c|c|c|c|c|}
\hline & \multicolumn{2}{|c|}{2008} & \multicolumn{2}{|c|}{2009} & \multicolumn{2}{|c|}{2010} \\
\hline & $\begin{array}{l}\text { Children } \\
2^{\text {nd }} \mathrm{TOI}\end{array}$ & Parents & $\begin{array}{l}\text { Children } \\
2^{\text {nd }} \mathrm{TOI}\end{array}$ & Parents & $\begin{array}{l}\text { Children } \\
2^{\text {nd }} \mathrm{TOI}\end{array}$ & Parents \\
\hline \multicolumn{7}{|l|}{ "Specific" allergens } \\
\hline House dust mite (feces) & 55 & 42 & 41 & 56 & 47 & 62 \\
\hline Grass pollen, etc. & 59 & 55 & 84 & 109 & 73 & 82 \\
\hline Animals / animal hair & 19 & 15 & 22 & 24 & 28 & 22 \\
\hline Bee/wasp stings & 3 & 2 & 3 & 1 & 4 & 1 \\
\hline Nuts & 7 & 6 & 5 & 11 & 8 & 7 \\
\hline Kiwi & 2 & 3 & 3 & 2 & 4 & 2 \\
\hline Penicillin & 2 & 4 & 1 & 2 & 2 & 5 \\
\hline "Specific" total & 147 & 127 & 159 & 205 & 166 & 181 \\
\hline \multicolumn{7}{|l|}{ "Nonspecific" triggers } \\
\hline Sun allergy & 19 & 10 & 12 & 19 & 7 & 8 \\
\hline Citrus fruits & 7 & 3 & 6 & 6 & 7 & 3 \\
\hline Other fruit & 3 & 2 & 8 & 6 & 5 & 6 \\
\hline Other foods & 12 & 7 & 10 & 14 & 12 & 10 \\
\hline Care products, etc. & 11 & 5 & 14 & 9 & 15 & 4 \\
\hline Other drugs & 2 & 2 & 4 & 4 & 5 & 1 \\
\hline Other insect bites & 7 & 4 & 8 & 7 & 8 & 6 \\
\hline Others & 10 & 4 & 20 & 19 & 11 & 14 \\
\hline Not specified & 18 & 18 & 27 & 7 & 19 & 21 \\
\hline "Nonspecific" total & 89 & 55 & 109 & 91 & 89 & 73 \\
\hline Total & 236 & 182 & 268 & 296 & 255 & 254 \\
\hline
\end{tabular}

Two results were particularly striking: Firstly, only around a third of children at the first TOI believed (correctly) that it is possible to participate in sports despite suffering from asthma; this proportion doubled to around two thirds of children at the second TOI. Secondly, only around $40 \%$ of children initially believed (correctly) that atopic dermatitis is not infectious; by the second TOI, this number had also doubled, reaching $80 \%-85 \%$. When questioned about how to behave in the case of an asthma attack, only around $15 \%$ of children answered correctly - after the education program, however, $45 \%-50 \%$. Similar increases in knowledge were also seen for the other questions. These effects were observed in all 3 project years; the McNemar test yielded significant differences $(p<0.001)$ for all 3 years (Tab. 4).

\section{Health satisfaction}

The following was a universal question in the KIDSCREEN"-10 Index: "How would you describe your general health?” with potential answers rang- ing from 1 for “excellent” to 5 for “poor.” Again, as with the questions on knowledge, this item was only compared in those children for whom responses at both the first and second TOI were available. Analysis was also differentiated on the basis of children "affected" and "not affected" by an allergic disease.

This yielded an improvement in mean values among "not affected" children from 2.1 to 1.9 , among "affected" children from approximately 2.5 to 2.3 , and for all children from 2.3 to 2.0 (all values significant in the Wilcoxon test).

\section{Follow-up survey}

The enduring effects of the education program were evident in the follow-up survey conducted in 2011 among the children that had taken part in the 2010 survey. Although only around $43 \%$ of children had responded correctly to questions $4-7$ at the first TOI in 2010, this percentage rose to $82 \%$ at the second TOI and was still $75 \%$ among the same pupils a year later in 2011 [9]. 
Tab. 4: Questions on children's knowledge and understanding of allergic diseases

\begin{tabular}{|c|c|c|c|}
\hline & 2008 & 2009 & 2010 \\
\hline Respondents* & $n=1,028$ & $\mathrm{n}=905$ & $n=685$ \\
\hline \multicolumn{4}{|c|}{ Does asthma cause the inner airways to narrow? (Correct answer: yes) } \\
\hline $1^{\text {st }} \mathrm{TOI}$ & 49.4 & 49.7 & 50.8 \\
\hline $2^{\text {nd }} \mathrm{TOI}$ & 87.7 & 88.0 & 89.6 \\
\hline
\end{tabular}

Are you allowed to do sports if you have asthma? (Correct answer: yes)

\begin{tabular}{|l|l|l|l|}
\hline $1^{\text {st }}$ TOI & 34.1 & 28.3 & 33.9 \\
\hline $2^{\text {nd }} \mathrm{TOI}$ & 66.3 & 64.6 & 73.3
\end{tabular}

\begin{tabular}{l|l|l|l}
$2^{\text {nd }} \mathrm{TOI}$ & 66.3 & 64.6 & 73.3
\end{tabular}

Is atopic dermatitis a skin disease? (Correct answer: yes)

\begin{tabular}{|c|c|c|c|}
\hline $1^{\text {st }} \mathrm{TOI}$ & 53.9 & 47.5 & 46.3 \\
\hline $2^{\text {nd }} \mathrm{TOI}$ & 76.0 & 78.0 & 81.2 \\
\hline \multicolumn{4}{|c|}{ Is atopic dermatitis contagious? (Correct answer: no) } \\
\hline $1^{\text {st }} \mathrm{TOI}$ & 47.9 & 41.1 & 40.0 \\
\hline $2^{\text {nd }} \mathrm{TOI}$ & 82.9 & 83.9 & 86.0 \\
\hline \multicolumn{4}{|c|}{ What are typical signs of allergy, asthma, or atopic dermatitis? (Percentage correct) } \\
\hline $1^{\text {st }} \mathrm{TOI}$ & 40.0 & 36.4 & 38.2 \\
\hline $2^{\text {nd }} \mathrm{TOI}$ & 59.4 & 61.9 & 64.4 \\
\hline
\end{tabular}

What should an asthmatic child with sudden respiratory distress do? (Percentage correct)

\begin{tabular}{|l|l|l|l|}
\hline $1^{\text {st }}$ TOI & 15.7 & 13.4 & 14.7 \\
\hline $2^{\text {nd }} \mathrm{TOI}$ & 45.7 & 42.8 & 51.5
\end{tabular}

What should a child with atopic dermatitis preferably do? (Percentage correct)

\begin{tabular}{|l|l|l|l|}
\hline $1^{\text {st }} \mathrm{TOI}$ & 18.2 & 12.6 & 14.7 \\
\hline $2^{\text {nd }} \mathrm{TOI}$ & 37.7 & 34.8 & 42.6 \\
\hline
\end{tabular}

TOI, time of investigation

*Relating to those children for whom questionnaires were linkable between the first and the second TOl; dichotomization of information into "predominantly correct" vs. "predominantly incorrect"; all data are significant $p<0.001$; statistical significance of before-and-after differences in the McNemar test, two-sided.
The corresponding KiGGS data - considered hitherto the most extensive and differentiated source for the prevalences of allergic diseases in children in Germany - show that the prevalences of "asthma, hay fever, and atopic dermatitis" in the "7to 10-year-old" age group are already close to the highest achievable rates in the various age groups [1], thus making the 9-years age group addressed in this study appear a useful target group. Data from large prospective birth cohorts also show that the highest prevalences of allergic asthma, atopic dermatitis, and food allergy have already been reached by this age, and that an additional increase is seen only for allergic rhinitis in the second decade of life $[10,11]$.

Our study was based on self-reported information provided by children on existing allergic diseases where applicable. Complementary medical examinations or inquiries at the responsible pediatrician or family physician were considered the gold standard. In lack of these, the corresponding data provided by the parents were used as a control. Considerable concordance was seen between data provided by parents and children. A Swedish study in 12-year-old children showed good concordance between the children's self-reported information and the data provided by their parents on allergic symptoms [12]. Prevalences in the KiGGS study in the corresponding "7- to 10-years" age group were based solely on parent information. A Norwegian study found high concordance rates between parent information and medical examinations for allergic diseases, whereby, interestingly, simple questions such as "Does your child suffer from asthma?" exhibited higher validity than those relating to specific asthma symptoms [13].

It is worthy of note that, although parent data on "allergies" and "asthma" indicated lower rates than that of their children, parents reported more "atopic dermatitis." Combined with the observation that children reported "atopic dermatitis" significantly more often at the second TOI compared with the first, this could mean that the children were either unaware of or preferred to conceal their disease prior to the education program. The fact that children were more likely to admit to this diagnosis and align themselves with their parents (more valid) information after the TS and the acceptance they experienced there speaks for the latter. The option in our study to make supplemental entries relating to allergens cannot be directly compared with the KiGGS, since the latter study performed quantitative detection of specific immunoglobulin (IgE) antibodies; this, however, was only reported cumulatively, or at least not differentiated according to the different allergens tested [1]. 
Given that around $50 \%$ of third graders in Bielefeld were surveyed, one can speak of good population-based coverage. KiGGS data were based on 167 single samples in urban vs. rural areas located throughout Germany. Although the basic publication differentiates between social and migration status, it does not take urban vs. rural environment into consideration. Selection effects were possible due to the voluntary participation in our study of schools assumed to have varying social backgrounds. A separate analysis of the catchment areas for the relevant primary schools based on social data made available on a small scale by the City of Bielefeld showed no associations between social or migration status and allergy prevalence from which generalized conclusions could be drawn [14]. The KiGGS data indicate higher allergy prevalences among children of higher social status or without a migrant background (attributed, among others, to greater recourse to medical care).

The prevalences found in our study, with around $25 \%-30 \%$ of children affected, are quantitatively higher compared with the comparable data (7- to 10 -years age group) from the two KiGGS surveys [1, 4]. However, this discrepancy can be largely explained by the use of a different term for allergy: while the KiGGS asked explicitly about "hay fever, we accepted all allergies. Reducing our prevalences, however, to only those with "pollen" in the allergen information yields comparable prevalences. It has also to be pointed out that the KiGGS, like our study - in the "parent-information only" 7- to 10-years age group - asked parents about a 12-month prevalence, whereas no such time limit was put on our children.

The results of annual school entry health examinations [15] reported in the Nordrhein-Westfalen Center for Health ("Landeszentrum Gesundheit Nordrhein-Westfalen", LZG.NRW) put the 20112013 figures at $1.6 \%-2.1 \%$ for "allergic rhinitis," $2.2 \%-2.6 \%$ for "bronchial asthma," and $2.8 \%-3.0 \%$ for "eczema." Remarkably, these figures are on the whole $50 \%$ lower compared with KiGGS data for the corresponding " 3 - to 6 -years" age group $[1,4]$. A recent study found prevalences for asthma of $4.7 \%$, hay fever $10.0 \%$, and atopic dermatitis $13.3 \%$ - „doctor-diagnosed“ according parent information - in primary school children aged 8.5 years in Innsbruck [16]. A 2005/2006 French study found an asthma prevalence (regarding treatment in the last 12 months) of already $9.9 \%$ in children aged just under 6 years, at the transition from nursery school to school [17].

In terms of affected children, it is established that well-founded asthma education is effective on several levels, e. g., symptom control and the reduction of absenteeism [18]. Many children affected by asthma and other allergic diseases, in particular atopic dermatitis, have already participated in education programs of this kind. To our knowledge, the present study was the first in Germany to also primarily address non-affected children. The project was able to stimulate considerable interest and achieved a marked increase in knowledge. However, a health technology assessment (HTA) report summarized that, although it was possible to improve children's knowledge, changing their attitudes and behaviors is a more challenging task [19] - a phenomenon not unknown in health promotion. Nevertheless, one should take advantage of the possibilities in the school context to promote children's health $[5,20]$.

Our 2011 follow-up study demonstrated that the increase in knowledge was sustained, i.e., the children's level of knowledge decreased only slighthly, from $82 \%$ correct answers after the TS 1 year previously to $75 \%$, but remained well above the $37 \%$ recorded prior to the TS [9]. Comparative data for other specialist subjects in primary school education are not available.

In particular pupils with asthma are frequently excused from school sports, since parents, teachers, and family physicians misjudge the children's exercise capacity or have concerns about adverse incidents [6]. However, it is generally accepted that deterring asthmatic children from sports and exercise is "fatal," and that an age-appropriately active way of life can contribute significantly to successful asthma management [21]. Too little is expected of asthmatic children in physical education at school, and rather than their exclusion appearing justified, it serves to stigmatize them further [22]. Training programs to promote physical exercise among children and adolescents reduce hospitalization periods, the frequency of asthma attacks, absenteeism from school, the number of visits to doctors, as well as medication use [23]. Teaching personnel need to be included in such programs in order to ensure that lessons are structured appropriately for affected children on the one hand, and that the correct response is given in the case of an acute asthma attack on the other $[24,25]$.

Epidemiological studies to date on the health status and behavior of children and adolescents in German-speaking countries have paid little attention to subjective health parameters, such as health-related quality of life [26]. Chronic disease received no particular attention in an initial KiGGS analysis of risks and resources for children's psychological development [27]. As recently as 2009, it was still being reported that most publications on healthrelated quality of life in children dealt with - comparatively far rarer - diseases in the fields of oncology and transplantation medicine, and only rarely addressed asthma and other common chronic diseases [28]. This gap is gradually closing, for instance 
in relation to quality of life among food-allergic children. A recent overview looked first at the restrictions placed on affected children in daily life, went on to discuss the risks of the often unexpected onset of medical incidents, including anaphylaxis, and concluded by compiling a broad list of the possible interactions in the family and wider social environment, e.g., school [29]. A number of instruments have been developed to collect data on health-related quality of life especially in the field of food allergies, while this appears to be the exception for asthma [30]. With KIDSCREEN-10, on the other hand, we have used a comprehensive instrument that is now well validated [31] and which was also applied in the KiGGS study (however, a comparison of our KIDSCREEN results with KiGGS is not possible, since KiGGS data have been converted to a different scale).

Reference is made in our original publication [8] to other relevant school projects and concepts. Particularly worthy of note is, e.g., the project initiated by the German Respiratory Tract League ("Deutsche Atemwegsliga e. V.”), "Gleiche Chancen!? Asthma in der Schule" ("Equal Chances!? Asthma at School") $[6,33]$, which aims, among other things, to reduce or compensate for the existing disadvantages experienced by affected children and adolescents and, in collaboration with schools, to create an equal opportunities basis to ensure equal participation in social life in school and free time. Given the relevance of the problem to society as a whole, as well as the positive experience with our project to date, it would be desirable for further initiatives of this kind to be set-up or expanded.

\author{
Reinhard Bornemann, MD, DrPH, PhD \\ Working group 2: Public Health Medicine \\ Faculty of Health Sciences \\ Bielefeld University \\ Universitätsstraße 25 \\ 33615 Bielefeld \\ Germany \\ E-Mail: bornemann@uni-bielefeld.de
}

\section{Acknowledgments}

The authors would like to thank Susanne Behr (Pediatric Allergology/Pneumology, Children's Center Bethel, Bielefeld Evangelical Hospital), Anja Böllhoff (Chairwoman of the Bielefeld Community Foundation until 2015), Jutta Schattmann (Director of the Bielefeld School Authority until 2012), Reinhard Samson (IT, Faculty of Health Sciences, Bielefeld University), and Dr. August Wolff GmbH \& Co. KG Arzneimittel for their generous support of this project.

\section{Conflict of interest}

The authors state that there are no conflicts of interest

\section{Cite this as}

Bornemann R, Hagemeister K, Bresser HG, Hamelmann E. Allergy and school: nothing to be sneezed at! A primary school project in Bielefeld, Germany, on epidemiology and health promotion in allergic diseases. Allergo $\mathrm{J}$ Int 2016;25:201-9

DOI: 10.1007/s40629-016-0131-3

\section{References}

1. Schlaud M, Atzpodien K, Thierfelder W. Allergische Erkrankungen. Ergebnisse aus dem Kinder- und Jugendgesundheitssurvey (KiGGS). Bundesgesundheitsbl Gesundheitsforsch Gesundheitsschutz 2007;50:701-10

2. Schmitz R, Thamm M, Ellert U, Kalcklösch M, Schlaud M. Verbreitung häufiger Allergien bei Kindern und Jugendlichen in Deutschland: Ergebnisse der KiGGS-Studie Erste Folgebefragung (KiGGS Welle 1). Bundesgesundheitsbl Gesundheitsforsch Gesundheitsschutz 2014;57:771-8

3. Hölling H, Schlack R, Dippelhofer A, Kurth BM. Personale, familiäre und soziale Schutzfaktoren und gesundheitsbezogene Lebensqualität chronisch kranker Kinder und Jugendlicher. Bundesgesundheitsbl Gesundheitsforsch Gesundheitsschutz 2008;51:606-20

4. Schmitz R, Ellert U, Thamm M. Erkrankungsbedingte Fehlzeiten und Lebensqualität von Kindern und Jugendlichen mit atopischen Erkrankungen in Deutschland Ergebnisse der KiGGS-Studie. 8. Deutscher Allergiekongress. 5.-7. September 2013, Bochum. Allergo J 2013;6:390-1

5. Ministerium für Schule und Weiterbildung des Landes Nordrhein-Westfalen, ed. Lehrplan Sachunterricht. In: Richtlinien und Lehrpläne für die Grundschule in Nordrhein-Westfalen. 1st Aufl. Düsseldorf, 2008;37-51. http:// www.schulentwicklung.nrw.de/lehrplaene/upload/klp_ gs/LP_GS_2008.pdf

6. Anonymus/ohne Autor. Projekt "Allergie und Schule" http://evkb.de/ueber-das-evkb/projekte/projekte/ projekt-allergie-und-schule

7. Erhart M, Ottova V, Gaspar T, Jericek H, Schnohr C, Alikasifoglu $\mathrm{M}$ et al. Measuring mental health and well-being of school-children in 15 European countries using the KIDSCREEN-10 Index. Int J Public Health 2009;54 (Suppl 2):160-6

8. Bornemann R, Hagemeister K. Allergie und Schule - Was juckt mich das? Ein Grundschulprojekt in Bielefeld zur Gesundheitsförderung bei allergischen Krankheiten. Gesundheitswesen 2013;75:51-8

9. Tiemann J. Gesundheitsförderung im Kindesalter am Beispiel eines Grundschulprojektes in Bielefeld (Bachelorarbeit an der FH Bielefeld). FH Bielefeld, 2011

10. Gough H, Grabenhenrich L, Reich A, Eckers N, Nitsche O, Schramm D et al. Allergic multimorbidity of asthma, rhinitis, and eczema over 20 years in the German birth cohort MAS. Pediatr Allergy Immunol 2015;26:431-7

11. Grabenhenrich LB, Keil T, Reich A, Gough H, Beschorner J, Hoffmann $U$ et al. Prediction and prevention of allergic rhinitis: a birth cohort study of 20 years. J Allergy Clin Immunol 2015;136:932-40 e12

12. Danell CS, Bergström A, Wahlgren CF, Hallner E, Böhme $\mathrm{M}$, Kull I. Parents and school children reported symptoms and treatment of allergic disease differently. J Clin Epidemiol 2013;66:783-9

13. Hansen TE, Evjenth B, Holt J. Validation of a questionnaire against clinical assessment in the diagnosis of asthma in school children. J Asthma 2015;52:262-7

14. Ekrot V. Der Einfluss des sozioökonomischen Status auf die Gesundheit von Kindern (Bachelorarbeit an der FH Bielefeld). FH Bielefeld, 2011 
15. Landeszentrum Gesundheit Nordrhein-Westfalen (LZGNRW), ed. Schulgesundheit (Reporte 2011-2013). https:// www.lzg.nrw.de/themen/gesundheit_berichte_daten/ schulgesundheit

16. Horak E, Morass B, Ulmer H, Genuneit J, Braun-Fahrlander C, Mutius E von. Prevalence of wheezing and atopic diseases in Austrian schoolchildren in conjunction with urban, rural or farm residence. Wien Klin Wochenschr 2014;126:532-6

17. Delmas MC, Guignon N, Leynaert B, Annesi-Maesano I, Com-Ruelle L, Gonzalez L et al. [Prevalence and control of asthma in young children in France]. Rev Mal Respir 2012;29:688-96

18. Szczepanski R, Petermann F, Freidel K, Becker PN, Gebert $\mathrm{N}$, Lob-Corzilius T. Die Wirksamkeit der Asthmaschulung bei Kindern und Jugendlichen. Kinderarzt 1998;29: 1201-8

19. Lister-Sharp D, Chapman S, Stewart-Brown S, Sowden A. Health promoting schools and health promotion in schools: two systematic reviews. Health Technol Assess 1999;3:1-207

20. Naidoo J, Wills J. Gesundheitsförderung in Schulen. In: Naidoo J, Wills J; Bundeszentrale für gesundheitliche Aufklärung (BZgA), eds. Lehrbuch der Gesundheitsförderung. 2nd Aufl. Gamburg: Verlag für Gesundheitsförderung; 2010; p. 315-29

21. Lecheler J. Sport und Bewegung bei asthmakranken Kindern. Pneumologe 2008;5:74-83

22. Meyer A, Machnick MA, Behnke W, Braumann KM. Teilnahme von asthmakranken Kindern am Schulsport - Eine Erhebung an Hamburger Schulen. Pneumologie 2002;56:486-92

23. Kemper P. Asthma bronchiale und Sport - Risiko und Chance. Pneumologie 2008;62:367-71

24. Forck I, Märzhäuser A, Weisser B. Wissensstand der sportunterrichtenden Grundschullehrer/innen in Schleswig-Holstein über Asthma bronchiale. Pneumologie 2008;62:226-30
25. Szczepanski R, Brockmann G. Gleiche Chancen!? - Asthma in der Schule: Herausforderungen für Familie und Lehrer. Pneumologie 2012;66:P157

26. Ravens-Sieberer U, Ellert U, Erhart M. Gesundheitsbezogene Lebensqualität von Kindern und Jugendlichen in Deutschland - Eine Normstichprobe für Deutschland aus dem Kinder- und Jugendgesundheitssurvey (KIGGS). Bundesgesundheitsbl Gesundheitsforsch Gesundheitsschutz 2007;50:810-8

27. Erhart $M$, Hölling $H$, Bettge $S$, Ravens-Sieberer $U$, Schlack R. Der Kinder- und Jugendgesundheitssurvey (KiGGS): Risiken und Ressourcen für die psychische Entwicklung von Kindern und Jugendlichen. Bundesgesundheitsbl Gesundheitsforsch Gesundheitsschutz 2007;50:800-9

28. Felder-Puig R, Topf R, Maderthaner R, Gadner H, Formann AK. Konzept der "gesundheitsbezogenen Lebensqualität" in der Pädiatrie - Nutzen für die Gesundheitsfürsorge, -forschung und -planung? Monatsschr Kinderheilkd 2009;157:675-82

29. Lange L. Lebensqualität bei Anaphylaxie und Nahrungsmittelallergie. Allergo J Int 2014;23:252-60

30. Silva N, Carona C, Crespo C, Bullinger M, Canavarro MC. The Portuguese DISABKIDS Asthma Module: a global index of asthma-specific quality of life for children and adolescents. J Asthma 2014;51:645-51

31. Ravens-Sieberer U, Herdman M, Devine J, Otto $C$ Bullinger $M$, Rose $M$ et al. The European KIDSCREEN approach to measure quality of life and well-being in children: development, current application, and future advances. Qual Life Res 2014;23:791-803

32. Ellert U, Brettschneider AK, Ravens-Sieberer U. [Health-related quality of life in children and adolescents in Germany: results of the KiGGS study: first follow-up (KiGGS Wave 1)]. Bundesgesundheitsbl Gesundheitsforsch Gesundheitsschutz 2014;57:798-806

33. Brockmann G, Szczepanski R. Gleiche Chancen!? Asthma in der Schule - Abschlussbericht. Osnabrück; 2012 